\title{
Ultra-Wideband Microstrip Bandpass Filter and Its Equivalent Circuit
}

\author{
Shita Fitria Nurjihan ${ }^{1}$, Yenniwarti Rafsyam ${ }^{2}$
}

\begin{abstract}
Microstrip filters can be designed with various method to obtain good performances, such as defected ground structure, open-ended slot, planar edge coupled, and split ring resonator with groundplane windowing. In this paper, the design of an ultra-wideband microstrip bandpass filter used the defected ground structure (DGS) method by adding a circular slot to the groundplane. The addition of the circular slot was carried out to improve the value of $S$ parameter (return loss and insertion loss) from the initial filter design without a circular slot. In the simulation process, optimization was carried out by changing the value of filter component parameters such as patch length and thickness and circular slot width. The simulation results showed that the microstrip bandpass filter could pass frequencies in the range of $1.4 \mathrm{GHz}$ to $5.7 \mathrm{GHz}$ with the bandwidth response of 4.3 GHz. In addition, filter analysis could also be done with an equivalent circuit represented by lumped element components in the form of capacitors and inductors connected in series or parallel. The simulation results of the equivalent circuit had a wider bandwidth, which was able to pass frequencies in the range of $1.2 \mathrm{GHz}$ to $6.1 \mathrm{GHz}$ with a bandwidth response of $4.9 \mathrm{GHz}$.
\end{abstract}

Keyword-Defected Ground Structure, Bandpass Filter, Microstrip, Equivalent Circuit.

\section{INTRODUCTION}

Microstrip filters can be designed with various techniques to obtain good performance. Several studies using diverse techniques have been conducted [1]-[6]. Filter bandpass in [1] was designed by applying the combination of defected ground structure (DGS) technique and an open-ended slot. The technique was applied to increase the insertion losses in the passband area and had a fractional bandwidth of $45 \%$. Previous study has also conducted the implementation of planar edge coupled using DGS [2]. The result showed that the bandpass filter could pass a frequency range of $3.1 \mathrm{GHz}$ to $10.6 \mathrm{GHz}$ with an insertion loss of $-0.3 \mathrm{~dB}$ and a return loss of $-19 \mathrm{~dB}$. Meanwhile, another research has applied DGS to the bandpass to increase bandwidth [3]. The result shows that, with simple dimensions the bandpass, filter had a bandwidth of $4.55 \mathrm{GHz}$ in the frequency range of $1.4 \mathrm{GHz}$ to $5.95 \mathrm{GHz}$.

Besides using a microstrip filter, filter analysis can be carried out using an equivalent circuit represented by lumped element components in the form of capacitors and inductors [7]-[12]. An equivalent circuit of microstrip bandpass filter has been designed using capacitor components and inductors arranged in series and parallel [7]. The equivalent circuit and microstrip

1,2 Department of Electrical Engineering, Politeknik Negeri Jakarta, Jl. Prof. Dr. G. A. Siwabessy, Kampus UI, Depok 16425 INDONESIA (phone: 021-786353; e-mail: ${ }^{1}$ shita.fitrianurjihan@elektro.pnj.ac.id,

${ }^{2}$ yenniwarti.rafsyam@elektro.pnj.ac.id) filter simulation had the same results with the bandwidth of 1 GHz. After that, reference [8] has proposed DGS-based bandpass filter and its equivalent circuit to increase the filter characteristics. The bandpass filter worked in the frequency of $1.84 \mathrm{GHz}$ to $7.2 \mathrm{GHz}$. Moreover, in [9], the analysis of equivalent circuits for split ring resonator-based microstrip generates good performance in reverse and insertion losses.

This paper discusses the design of the microstrip bandpass filter and its equivalent circuit. Bandpass filter design consisted of four strips on the patch and a circular slot on the groundplane. Based on the simulation, the microstrip bandpass filter could pass frequency in the range of $1.4 \mathrm{GHz}$ to $5.7 \mathrm{GHz}$ with a bandwidth of $4.3 \mathrm{GHz}$. Meanwhile, the equivalent circuit could pass frequency in the range of $1.2 \mathrm{GHz}$ to $6.1 \mathrm{GHz}$ with a bandwidth of $4.9 \mathrm{GHz}$.

\section{BANDPASS FILTER DESIGN}

The design of the microstrip bandpass filter and its equivalence has three stages, namely the design of bandpass filter, bandpass filter with circular slot, and equivalent circuit, as seen in Fig. 1. In designing the microstrip bandpass filter, two initial stages were conducted, namely the design of a bandpass filter with a patch design consisting of four strips and a tapered feedline with simple dimensions of $27 \mathrm{~mm} \times 22 \mathrm{~mm}$. Using (1)-(4) [13], the filter dimensions for each component were obtained; bandpass filter design is shown in Fig. 2.

The results of the microstrip bandpass filter simulation indicates that it has not met the filter specifications. These results included generating return loss values which were close to $0 \mathrm{~dB}$ and insertion loss values which were below $0 \mathrm{~dB}$, as shown in Fig. 3. Hence, the filter design was changed.

By applying the defected ground structure (DGS) technique, in the microstrip bandpass filter design, a slot was added to the groundplane in the form of a circular slot. It is shown in Fig. 4. In the bandpass filter with a circular slot, the parameter on the filter component was changed to generate an optimal $S$ parameter.

For $w / h \leq 2$ namely

$$
\frac{w}{h}=\frac{8 e^{A}}{e^{2 A}-2}
$$

For $w / h>2$ namely

$$
\begin{gathered}
\frac{w}{h}=\frac{2}{\pi}\{(B-1-\ln (2 B-1)) \\
\left.+\left(\frac{\varepsilon_{r}-1}{2 \varepsilon_{r}}\left[\ln (B-1)+0,39-\frac{0,61}{\varepsilon_{r}}\right]\right)\right\}
\end{gathered}
$$

where

$$
A=\frac{Z_{0}}{60} \sqrt{\frac{\varepsilon_{r}+1}{2}}+\frac{\varepsilon_{r}-1}{\varepsilon_{r}+1}\left(0.23+\frac{0.11}{\varepsilon_{r}}\right)
$$




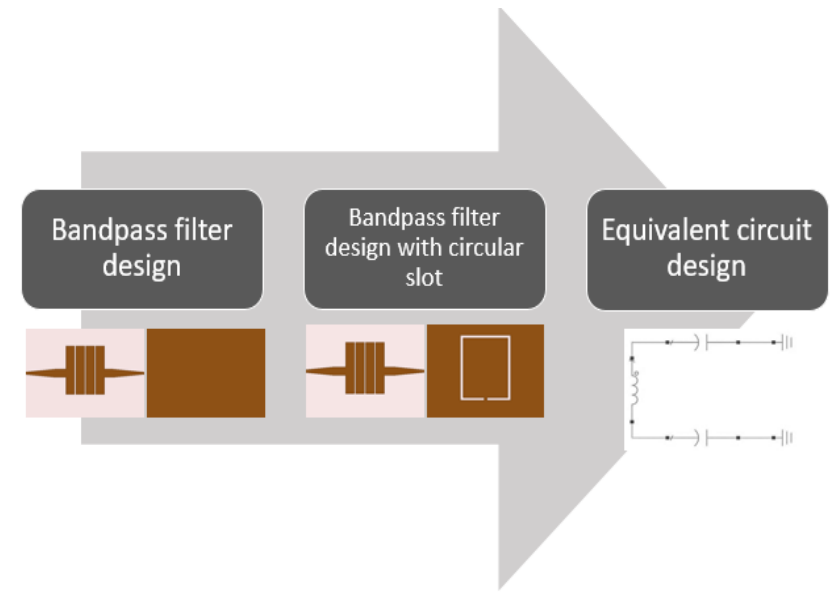

Fig. 1 Stages of designing a bandpass filter and its equivalent circuit.

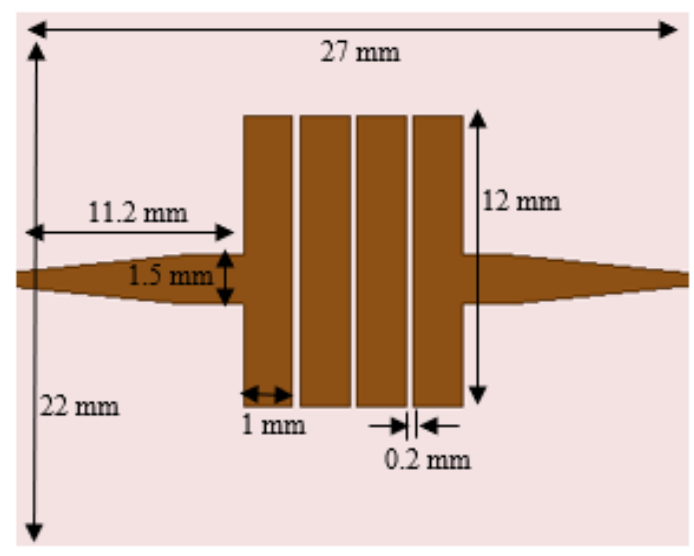

(a)

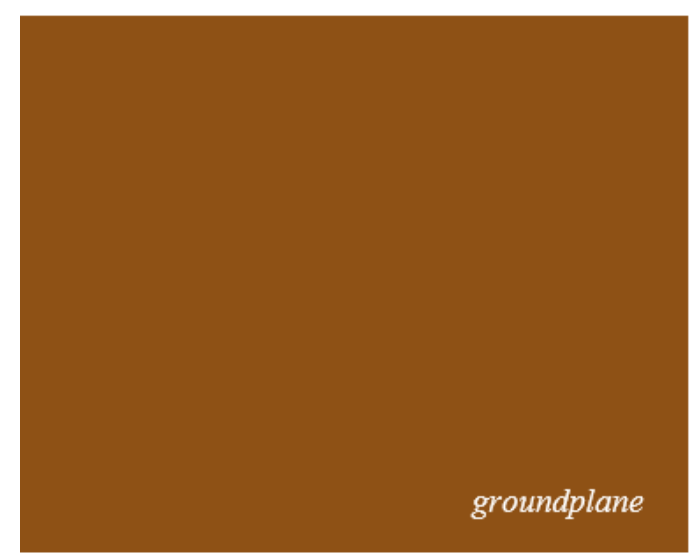

(b)

Fig. 2 Bandpass filter design, (a) front view and (b) back view.

$$
B=\frac{377 \pi}{2 Z_{0} \sqrt{\varepsilon_{r}}}
$$

\section{PARAMETER STUDY OPTIMIZATION}

The parameter changes in the bandpass filter component to generate an optimal $S$ parameter values was carried out by changing the parameter values for the patch length, patch width, circular slot width, and distance in the circular slot.

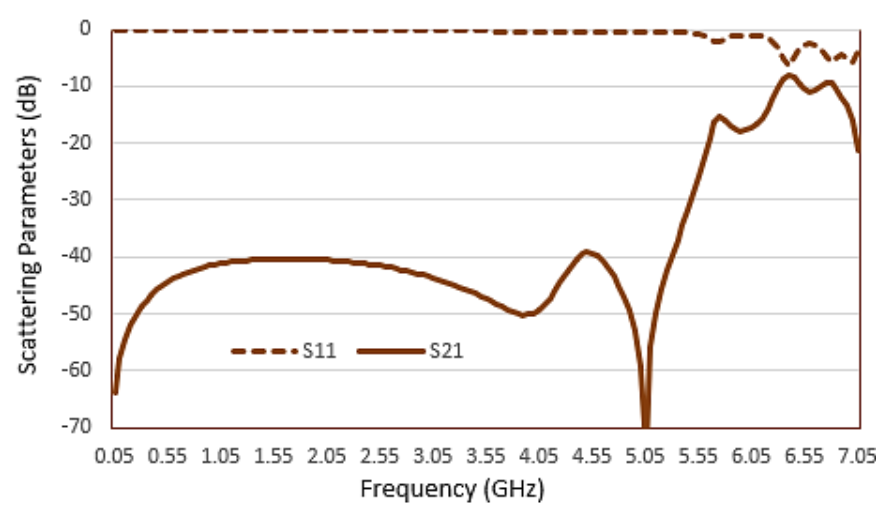

Fig. 3 Bandpass filter simulation result.

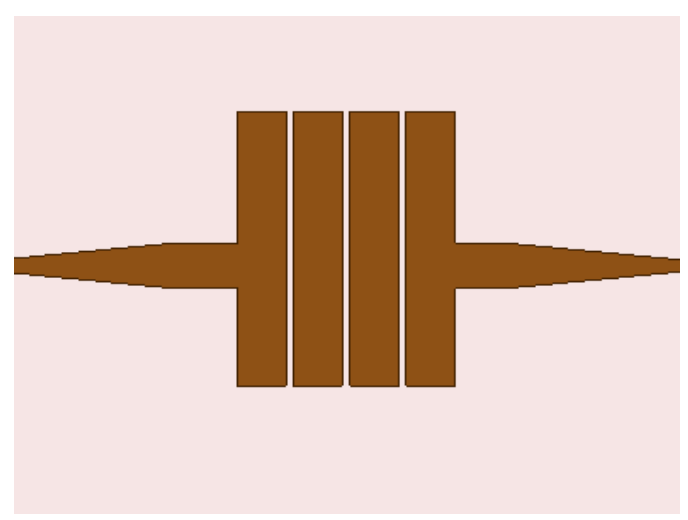

(a)

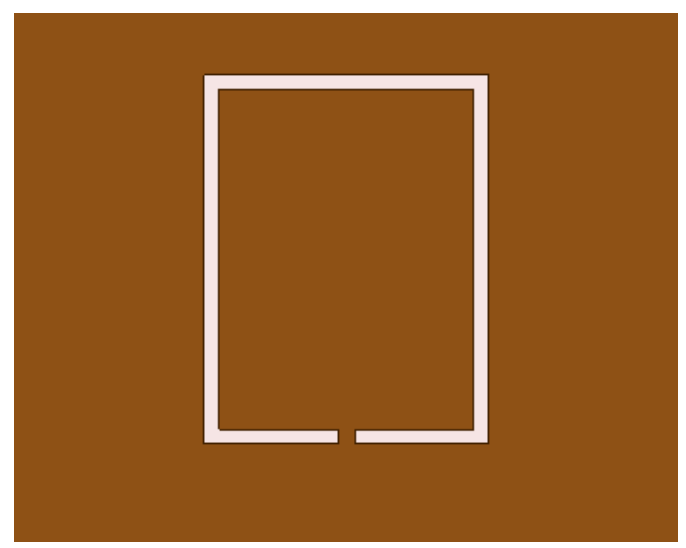

(b)

Fig. 4 Bandpass filter design with circular slot, (a) front view and (b) back view.

The parameter changes in the length of the patch, which is shown in Fig. 5, showed change variation with values of $0 \mathrm{~mm}$, $11 \mathrm{~mm}, 12 \mathrm{~mm}$, and $13 \mathrm{~mm}$. The simulation result indicates that the patch width in the microstrip bandpass filter design affects generated return losses. Meanwhile, the change in the patch length generated better return loss values for the patch with the length of $12 \mathrm{~mm}$.

After that, the change of the parameter in the width of the patch, which is shown in Fig. 6, showed change variation with values of $1 \mathrm{~mm}, 1.5 \mathrm{~mm}, 2 \mathrm{~mm}$, and $2.5 \mathrm{~mm}$. The simulation result suggests that patch width in the microstrip bandpass filter design affects return losses and bandwidth values produced. 


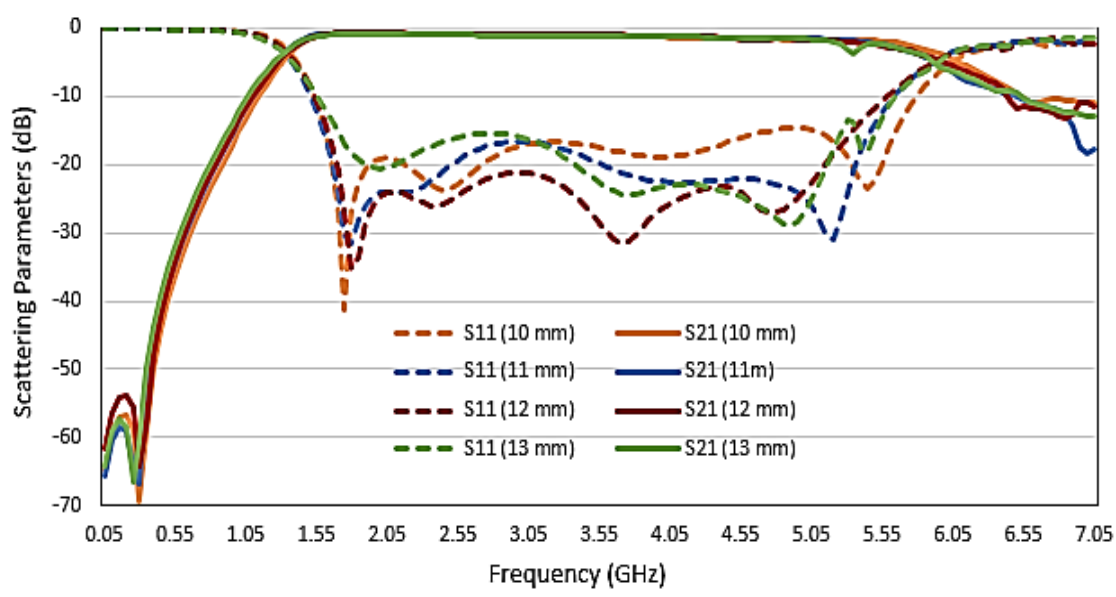

Fig. 5 Simulation result of changing patch length parameters.

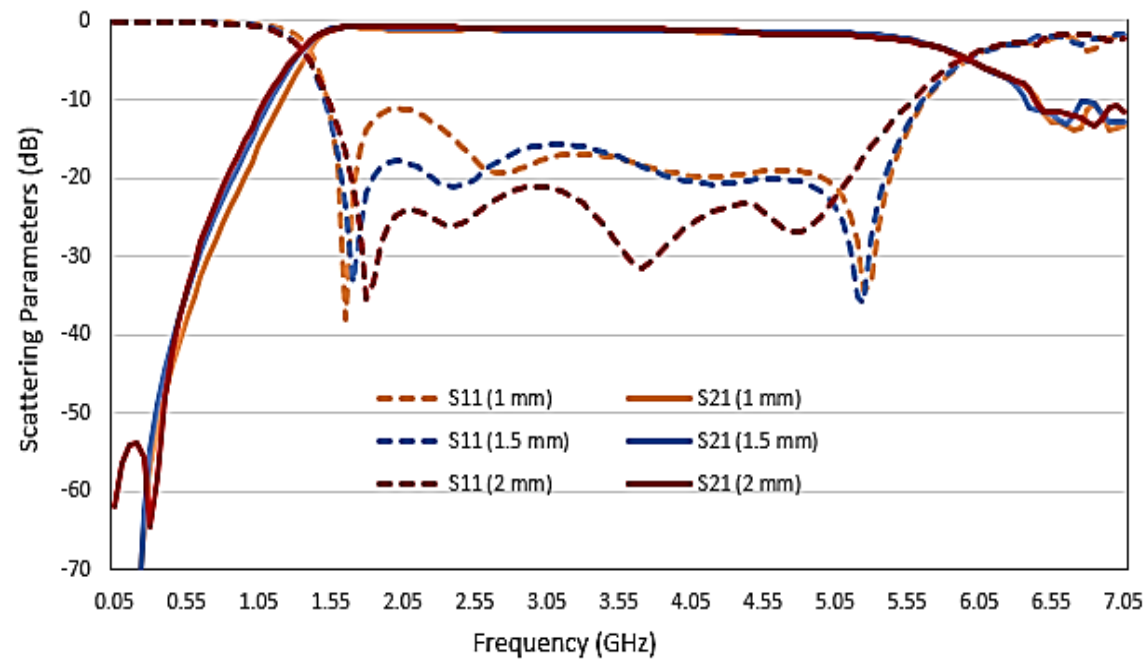

Fig. 6 Simulation result of changing patch width parameters.

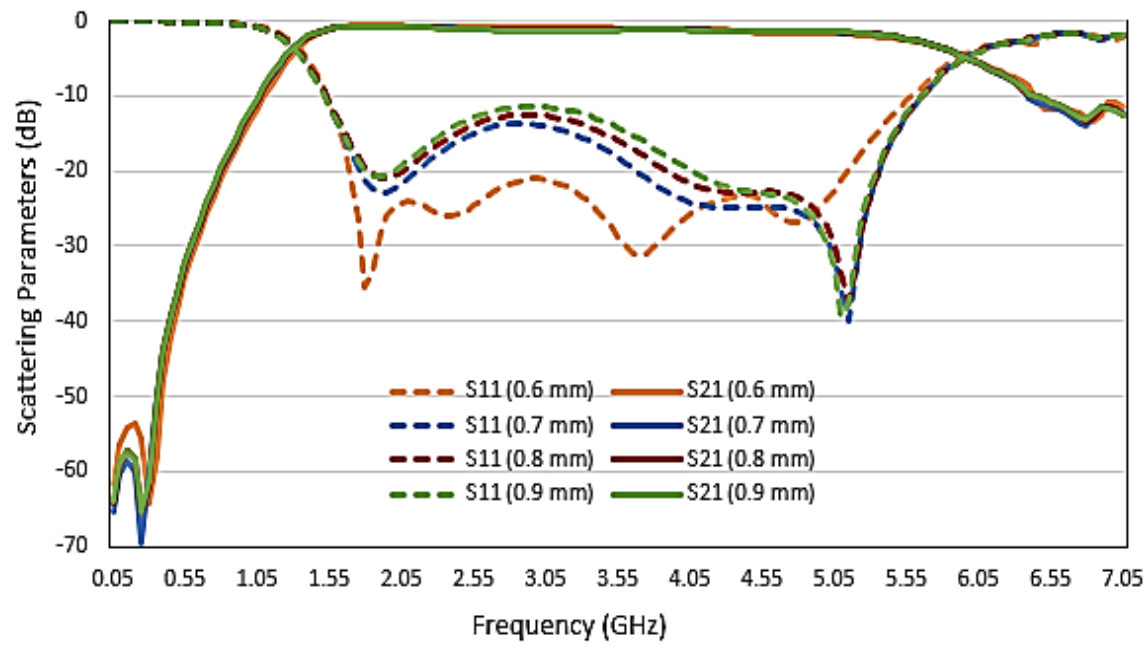

Fig. 7 Simulation result of changing circular slot width parameters.

The change in the patch width values generated better return loss values and wider bandwidth for the patch width of $2 \mathrm{~mm}$.

Fig. 7 shows the variation of the circular slot width change with values of $0.6 \mathrm{~mm}, 0.7 \mathrm{~mm}, 0.8 \mathrm{~mm}$, and $0.9 \mathrm{~mm}$. The simulation result shows that circular slot width in the microstrip bandpass filter design affects return loss values. Changing the circular slot width value resulted in better return loss values for the circular slot with the width of $0.6 \mathrm{~mm}$. 


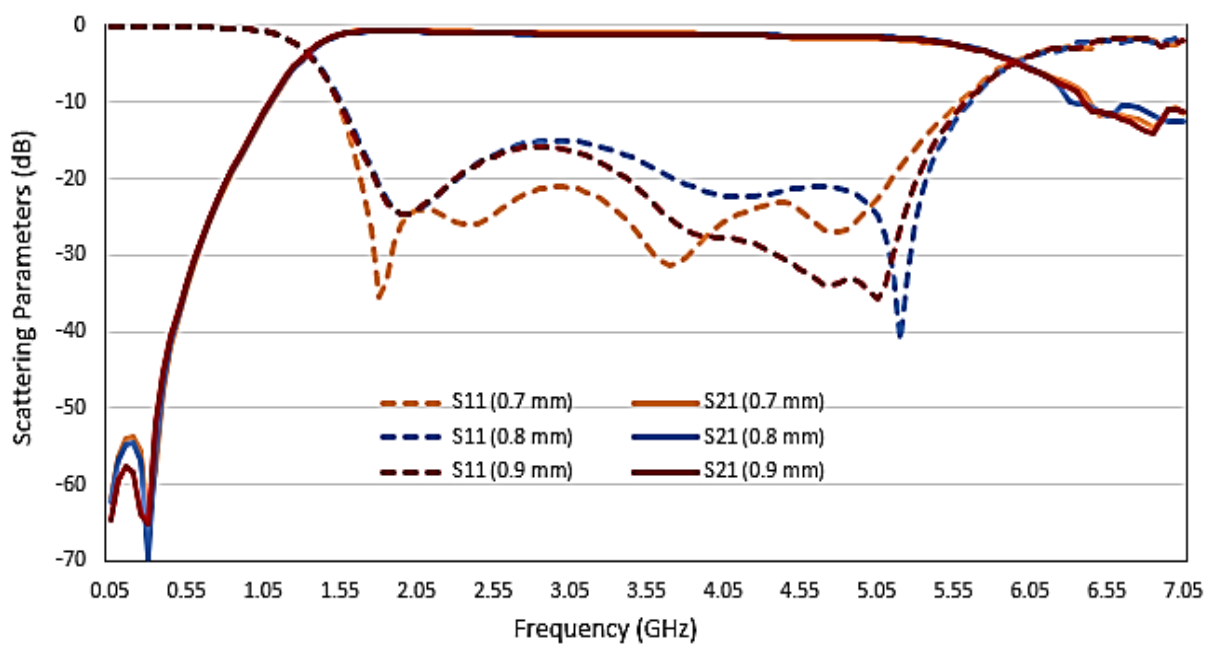

Fig. 8 Simulation result of the change of circular slot distance parameter.

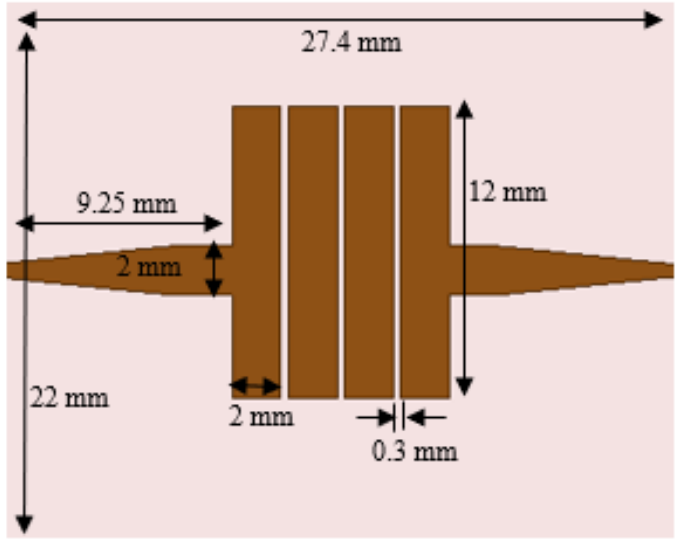

(a)

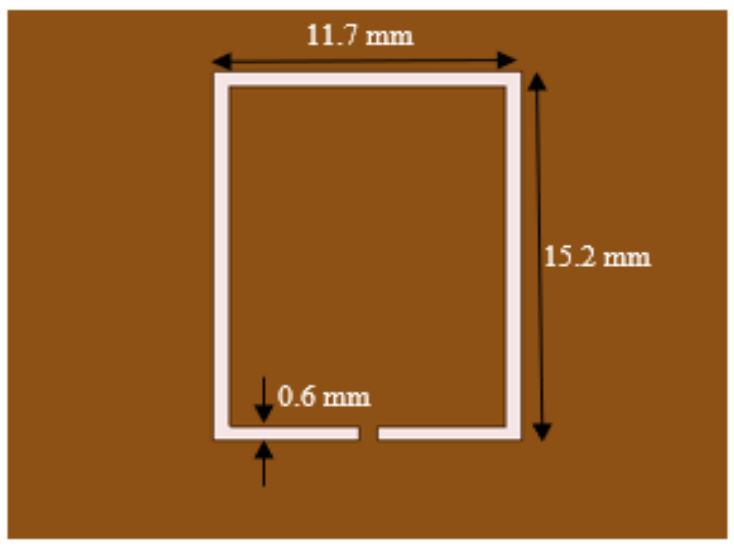

(b)

Fig. 9 Final design of bandpass filter with circular slot.

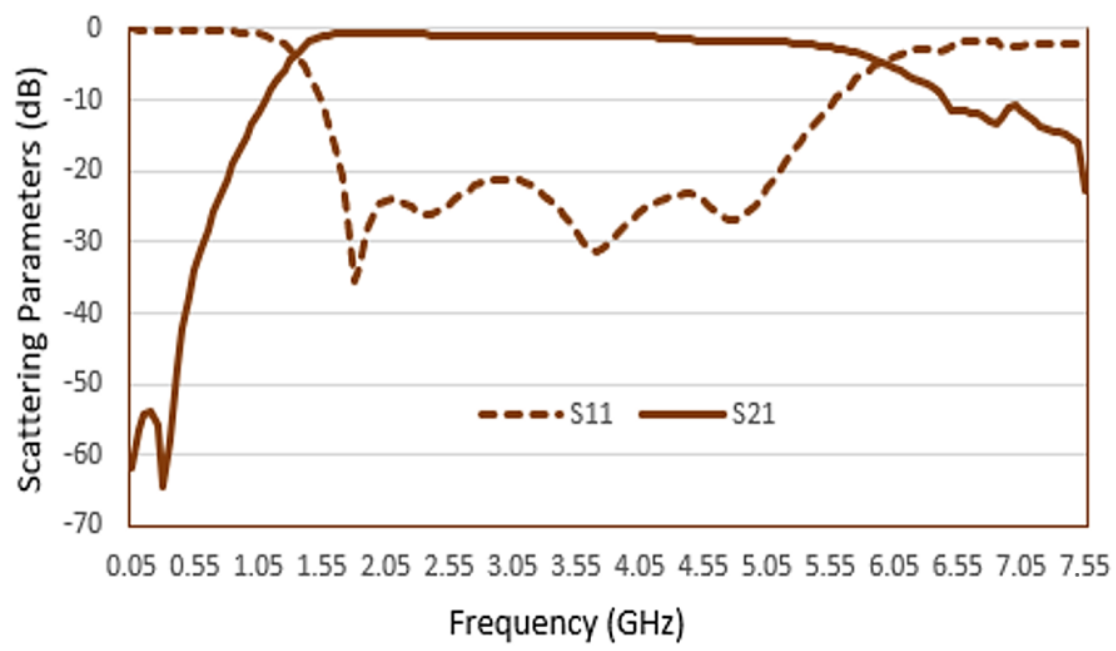

Fig. 10 Simulation results of bandpass filter with circular slot.

Fig. 8 shows change variations of the circular slot distance with values of $0.7 \mathrm{~mm}, 0.8 \mathrm{~mm}$, and $0.9 \mathrm{~mm}$. The simulation results indicates that the circular slot distance in the microstrip bandpass filter design affects the generated return losses. Moreover, the change in the values of the circular slot distance produced better return loss values for the circular slot with the distance of $0.7 \mathrm{~mm}$.

Parameters change in the several bandpass filter components gained optimal results for the filter dimension of $27.4 \mathrm{~mm} \times 22$ $\mathrm{mm}$, as presented in Fig. 9. Meanwhile, the simulation results 

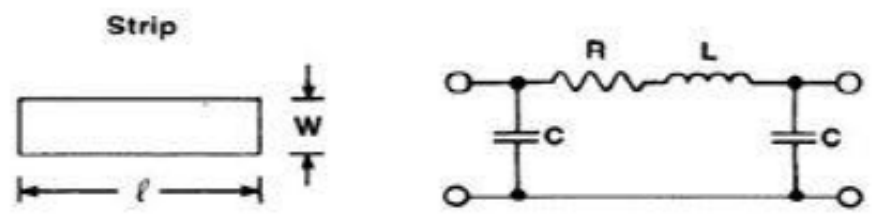

Fig. 11 Microstrip line and its substitute circuit [12].
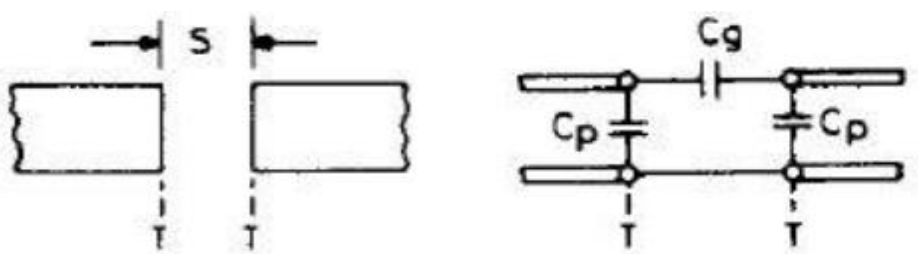

Fig. 12 Distance between channels and their substitute circuits [12].

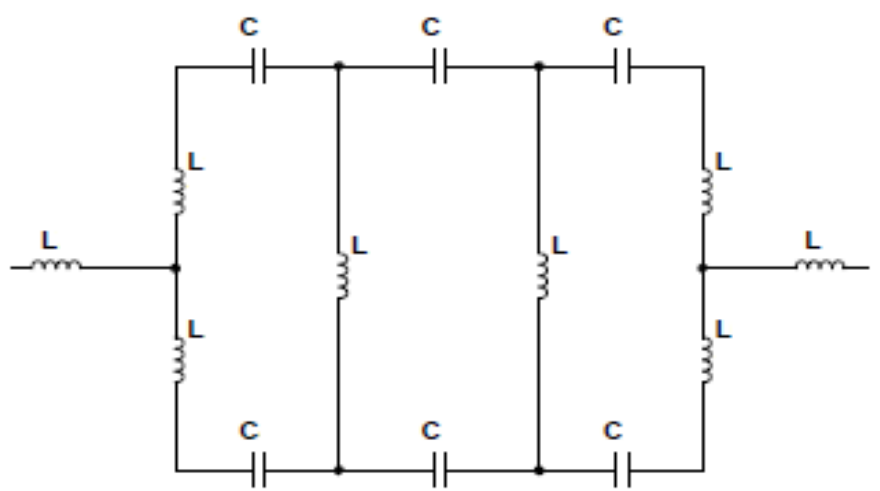

Fig. 13 Substitute circuit of four strips.

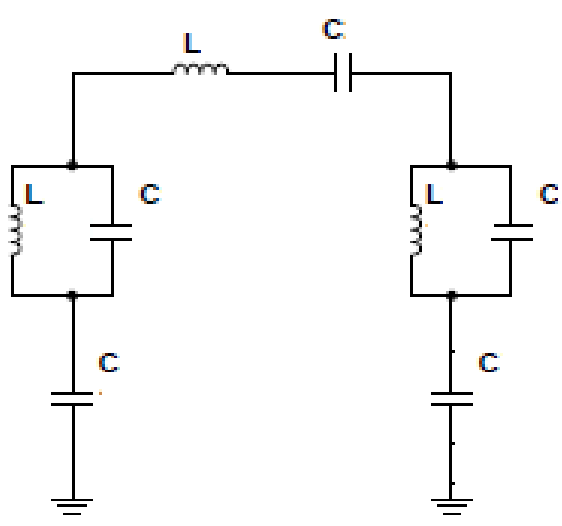

Fig. 14 Substitute circuit of circular slot.

of the bandpass filter worked in the frequency range of $1.4 \mathrm{GHz}$ to $5.7 \mathrm{GHz}$ with a bandwidth of $4.3 \mathrm{GHz}$ is shown in Fig. 10 .

\section{IV.EQuivalent CIRCUIT DESIGN}

Bandpass filter analysis can be carried out with an equivalent circuit which is represented using lumped element components in the form of capacitors and inductors connected in series or parallel. The equivalent circuit represents the components of the microstrip line and the distance between the lines or gaps. Inductor components can represent microstrip lines.
Meanwhile, capacitor components represent the distance between lines. The representation of the microstrip channel and the distance between the channels are shown in Fig. 11 and Fig. 12 [14].

The open circuit has a high impedance. As a result, the value of the current flowing through the microstrip line is very small. Meanwhile, the groundplane characteristics has a very low impedance so that the current flowing in the microstrip line produces an extremely high value. It is shown in (5)-(6) [15]. Therefore, if the open circuit is represented by an inductor 


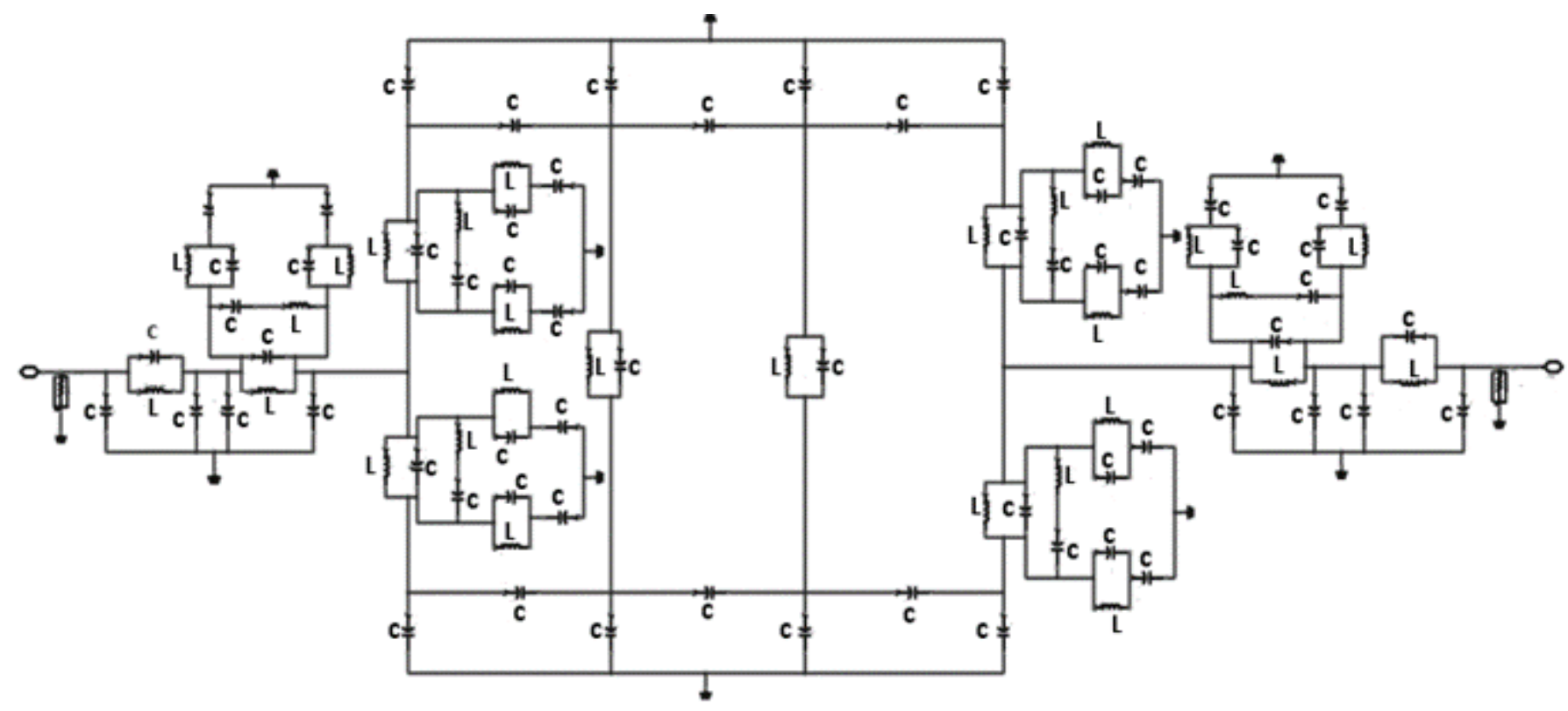

Fig. 15 Equivalent circuit of bandpass filter.

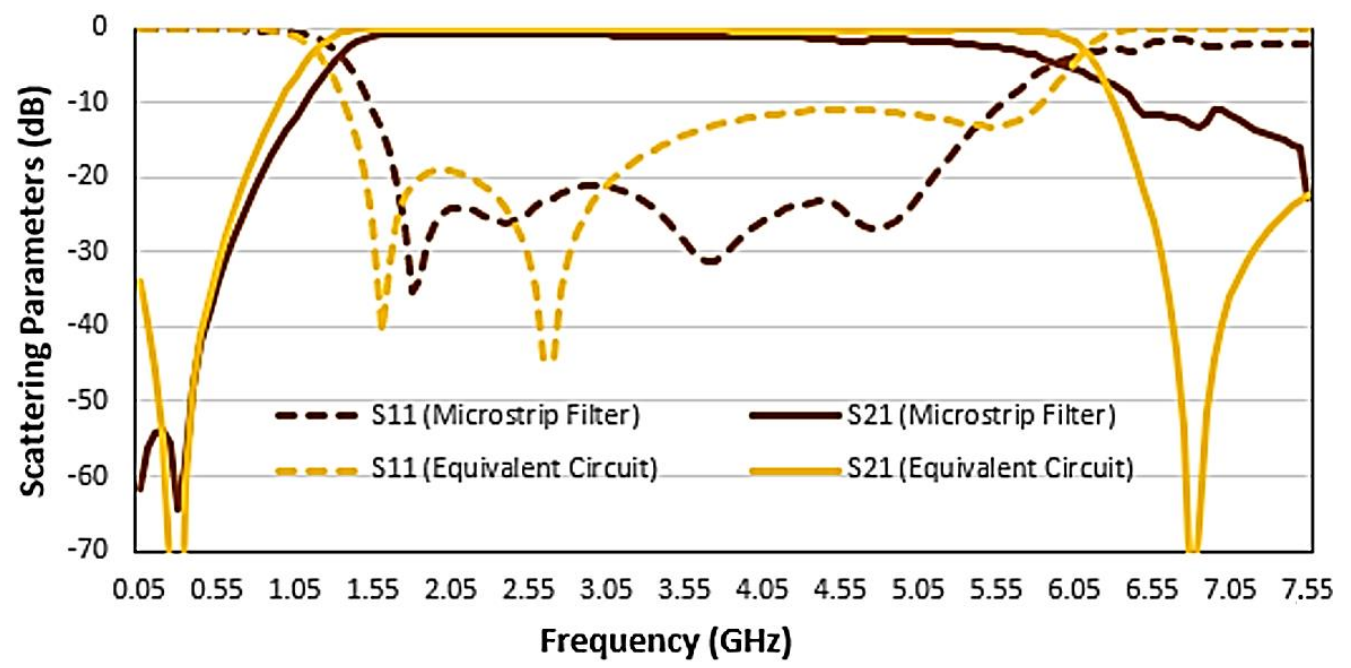

Fig. 16 Comparison of simulation results of a bandpass filter with a circular slot.

component, the inductor value will be very high. If the groundplane is represented by a capacitor component, the capacitor value will be very high.

$$
\begin{aligned}
& X_{C}=\frac{1}{j \omega C} \\
& X_{L}=j \omega L
\end{aligned}
$$

The equivalent circuit for the patch consisting of four strips and a tapered feedline can be seen in Fig. 13; four strips and the feedline are represented by the inductor component, while the gap between the strips is represented by a capacitor. The groundplane with circular slots is shown in Fig. 14. The equivalent circuit for the microstrip bandpass filter is presented in Fig. 15.

Fig. 16 presents the comparison results of the microstrip bandpass filter simulation and its replacement circuit. The simulation results had differences in the value of the $S$ parameter, namely the value of return losses and the value of insertion losses. The equivalent circuit had a better insertion loss value, which was close to $0 \mathrm{~dB}$ so that it had a wider bandwidth. It was due to the circuit was considered ideal and there was no attenuation in the simulation of the replacement circuit. The return loss values in the simulation of the equivalent circuit reached the value of up to $-10 \mathrm{~dB}$ at a certain frequency. It was influenced by the value of the lumped component of the capacitor and inductor elements in the structure of the equivalent circuit. The simulation results of the replacement circuit could pass frequencies in the range of 1.2 $\mathrm{GHz}$ to $6.1 \mathrm{GHz}$ with a bandwidth of $4.9 \mathrm{GHz}$.

\section{CONCLUSION}

In this paper, the microstrip bandpass filter with circular slots on the groundplane and its equivalent circuit has been designed. The addition of circular slots on the groundplane can 
improve the value of the $S$ parameter. In the parameter changes made, the return losses are affected by the length and width of the patch.

Bandpass filter analysis can be carried out with equivalent circuits for capacitors and inductors. The equivalent circuit in the circular slot affects the return losses. The simulation results of the microstrip filter and the replacement circuit have almost the same performance.

\section{REFERENCES}

[1] A. Ghosh and P. Mondal, "Bandpass Filter Using a Combination of DGS's and Open Ended Slot," 2018 2nd International Conference on Trends in Electronics and Informatics (ICOEI), May 2018, pp. 392-396.

[2] S. Lavanya, M.U. Maheshwari, E. Soundarya, A.G. Porkodi, K. Sophiya, and S. Kanthamani, "Planar Ultra Wideband Bandpass Filter Using defected ground structure," 2015 International Conference on Innovations in Information, Embedded and Communication Systems (ICIIECS), Mar. 2015, pp. 1-3.

[3] S.F. Nurjihan and A. Munir, "Effect of DGS Incorporation for Bandwidth Enhancement of UWB Microstrip BPF," Proceedings of 3rd International Conference on Wireless and Telematics (ICWT), Jul. 2017, pp. 39-42.

[4] S.F. Nurjihan and A. Munir, "Rancang bangun Filter Bandpass Mikrostrip Pita Sangat Lebar Berbasis Defected Ground Structure," Jurnal Nasional Teknik Elektro dan Teknologi Informasi, Vol. 9, No. 1, pp. $104-109$, Feb. 2020.

[5] S. Tantiviwat, M.S. Razalli, and S.Z. Ibrahim, "Miniature Microstrip Bandpass Filters Based on Quadruple-Mode Resonators with Less Via," 2017 IEEE MTT-S International Conference on Microwaves for Intelligent Mobility (ICMIM), 2017, pp. 1-4.

[6] D.S. Salgare and S.R. Mahardik, "A review of defected ground structure for microstrip antennas," International Research Journal of Engineering and Technology (IRJET), Vol. 2, No. 6, pp. 150-154, Sep. 2015
[7] X. Zhieng and X. Wang, "Design of Slot Coupled Microstrip Bandpass Filter Based on Defected Ground Structure (DGS)," 2019 18th International Conference on Optical Communications and Networks (ICOCN), Aug. 2019, pp. 1-3.

[8] A. Munir, B.D. Wulandari, W. Aditomo, and Y. Prasetio, "DGS-based UWB Microstrip BPF and Its Equivalent Circuit," 2017 9th International Conference on Computational Intelligence and Communication Networks (CICN), Sep. 2017, pp. 11-15.

[9] E.R Afthar, M.R. Hidayat, and A. Munir, "Analysis of equivalent circuit for bandpass filter based on SRR with groundplane windowing," Proceedings of Asia-Pacific Conference on Communications (APCC), 2016, pp. 361-364.

[10] A. Munir, E.R. Afthar, and R. Safitri, "Study on Equivalent Circuit of Wideband BPF Using Groundplane Windowed SRR and Its Realization," Proceedings of 7th International Annual Engineering Seminar (InAES), 2017, pp. 1-4.

[11] Y.D. Chen and C.H. Liu, "Exploiting Hi-Lo Inter-Digital DGS for HighOrder Microstrip Bandpass Filter," Asia-Pacific Conference on Antennas and Propagation (APCAP), 2016, pp. 83-84.

[12] Edwar and A. Munir, "Equivalent Circuit Analysis of Square-LoopResonator BPF with Cross-Shaped I/O Coupling for X-Band Frequency Aplication," International Conference on Control, Electronics, Renewable Energy and Communications (ICCEREC), 2017, pp. 66-69.

[13] D.K. Misra, Radio-Frequency and Microwave Communication Circuit: Analysis and Design, 2nd ed., Hoboken, USA: John Wiley \& Sons, Inc., 2004.

[14] K.C. Gupta, R. Garg, I. Bahl, and P. Bhartia, Microstrip Lines and Slotlines, 2nd ed., Norwood, USA: Artech House, 1996.

[15] C. Alexander and M. Sadiku, Fundamental of Electric Circuit, 4th ed., New York, USA: McGraw-Hill, 2009. 